\title{
OVERVIEW: ANÁLISE DAS AÇÕES DE RESPONSABILIDADE SOCIAL DA CREDSAT NO BAIRRO JARDIM NOVO BONGIOVANI EM PRESIDENTE PRUDENTE - SP
}

Alessandra Harumi Sakai dos Santos \#, Edilene Mayumi Murashita Takenaka\#\#, Alexandre Godinho Bertoncello.

Universidade do Oeste Paulista, Cursos: Mestrado em Meio Ambiente e Desenvolvimento Regional, Presidente Prudente, São Paulo. e-mail: alessandra.sakai@hotmail.com

\section{RESUMO}

A ação humana na intervenção dos focos de dengue deve ser constante. Isso implica desde os descartes corretos dos resíduos até a recolha dos mesmos. Adotar a consciência de fazer a diferença no meio em que habita, cumprindo seu papel social. O objetivo deste estudo foi perquirir a atuação em projetos de responsabilidade social numa pequena empresa do setor de tecnologia de Presidente Prudente no estado de São Paulo. A metodologia constou de pesquisa descritiva, abordagem qualiquantitativa, estudo de caso e a pesquisa bibliográfica com extensa revisão teórica. Os resultados foram 62 sacos de lixos recolhidos no período de 1 ano e meio. Os lixos recolhidos, englobaram sapatos, vidros, garrafas, fraudas, piscinas, fios diversos, caixas de cigarro, sacolas plásticas, etc. Concluímos que os resultados abrangeram o surgimento de mídia espontânea, a melhoria de imagem e o fortalecimento do pertencimento regional. As empresas que praticam o Responsabilidade Social, fortalecem a marca.

Palavras-chave: Mobilização, Responsabilidade Social, Meio Ambiente, Conscientização.

OVERVIEW: ANALYSIS IN THE OF SOCIAL RESPONSIBILITY ACTIONS OF THE CREDSAT IN THE NEIGHBORHOOD OF THE JARDIM NOVO BONGIOVANI IN THE PRUDENT PRESIDENT - SP

\section{ABSTRACT}

The human action in the intervention of the foci of dengue must be constant. This implies from the correct discards of the wastes to the until collection of the same. Adopt the awareness of making a difference in the environment in which you live, fulfilling your social role. The objective of this study was to investigate social responsibility projects in a small company in the technology sector of Presidente Prudente in the state of São Paulo. The methodology consisted of descriptive research, qualitative approach, case study and bibliographical research with extensive theoretical revision. The results were 62 bags of wastes collected in the period of $1 \frac{1}{2}$ years. The garbage collected included shoes, glasses, bottles, cigarettes, swimming pools, various threads, cigarette boxes, plastic bags, etc. We conclude that the results covered the emergence of spontaneous media, the improvement of image and the strengthening of regional belonging. Companies that practice Social Responsibility strengthen the brand.

Keywords: Mobilization, Social Responsibility, Environment, Awareness.

\section{INTRODUÇÃO}

Os órgãos governamentais estão limitados ao lidar com as questões relacionadas ao meio ambiente, pois ainda que se criem novas políticas e novas condutas, se os cidadãos não contribuírem, sua prática não será efetiva. A fim de lidar com essas questões deve se buscar os recursos da sociedade em apoio ao domínio público. Esforços não somente governamental, mas sim de todos os setores, abarcando empresas e cidadãos realizando 
sua responsabilidade social perante ao meio ambiente.

Muito se fala sobre a responsabilidade social, mas essa prática é rara, empresas podem usufruir de suas forças de resolução de problemas e ter iniciativas para tratar problemas sociais e ambientais e assim obter vantagem competitiva. Toda empresa visa destinar forças as suas atividades comerciais, e desfocam a responsabilidade social empresarial. Neste aspecto os valores e a consciências entra em cena, pois a realização de ações voluntarias são atitudes que servem de exemplo para a comunidade em que estão inseridas.

Hodiernamente, ações no combate à dengue vêm aumentando progressivamente, no entanto o aumento dos índices de casos de pessoas contaminadas pelo mosquito ainda é surpreendente.

O ambiente que se está inserido é de extrema importância para toda a sociedade. Atos humanos causam sérios problemas ao meio natural e podem levar a sérias consequências, muitas vezes irreversíveis. Resíduos sólidos de diversas categorias são despostos de maneira inapropriada, sem o devido consentimento ou consciência de seu resultado final. A poluição do solo, a contaminação, a enchente e principalmente a proliferação de vetores como o mosquito da Dengue, dentre outros vem causando enormes impactos socioambientais. A destinação incorreta de certos resíduos tem sido a grande causa desses incidentes, pois são grandes armazenadores de água. Qualquer recipiente com água parada atrai o mosquito Aedes Aegypti que se reproduz facilmente. Cuidar do meio ambiente é uma maneira de intervir na reprodução do mosquito.

Orientações e educação ambiental são constantes em vários municípios, mesmo assim, ainda é encontrado diversos focos de dengue. É imprescindível o engajamento do ser humano no processo da extinção e prevenção do mosquito Aedes Aegypt. Isso implica desde os descartes corretos dos resíduos até a recolha dos mesmos (descartados incorretamente por outras pessoas). Se a sociedade não se mobilizar, quem irá fazer? Deve se ter uma consciência de que cada um pode fazer a diferença no meio em que habita, cumprindo seu papel social frente ao meio ambiente.

A ausência de informações e a falta de conscientização de cada cidadão acarreta sérios problemas ao meio ambiente. Seres humanos podem contribuir para a mudança de diversos cenários, basta que eles estejam informados e conscientizados na preservação e manutenção do meio ambiente e da biodiversidade. A comunidade acredita que é de responsabilidade dos governos e instituições públicas promover a preservação ambiental e a sustentabilidade e esquece que cada um possui também um papel fundamental neste contexto.

Citar se á uma pessoa que se depara com um papel jogado no chão, passa por cima, mas não recolhe e joga no lixo. Nos países subdesenvolvidos como o Japão as pessoas devem fazer qualquer coisa que esteja ao seu alcance (atari mae), como por exemplo a obrigação de recolher qualquer papel ou lixo que encontrar em seu caminho.

Saldiva (p. 26, 2016) afirma que

Para induzir uma mudança de comportamento, temos de produzir a melhor ciência possível e, depois, fazer com que o conhecimento seja apoderado, em textos mais amigáveis, pela população em geral e pelos gestores. [...] Estruturas acadêmicas também podem ser eficientes em traduzir o conhecimento científico para o grande público e instrumentalizar a política.

Segundo Saldiva (2016), é preciso adotar mudanças de comportamento na sociedade. Se não mudar a mentalidade não é possível mudar um comportamento. Por isso o autor coloca a importância de divulgar a pesquisa, de apresentar resultados 
comprobatórios que foram realizados e podem ser replicados por outros.

Nos Estados Unidos, os estudos são publicados em grandes jornais e revistas com ênfase nos assuntos para chamar a atenção do público. O New York Times divulgou um estudo mostrando que quanto pior a mobilidade, menor o tempo que pessoas terão para estudar e menor será futuro. Isso está sendo discutido no congresso dos Estados Unidos. No Brasil é difícil fazer a passagem do conhecimento científico para outros públicos de forma profissional com eficiência. Pesquisadores acreditam que o trabalho acaba após a publicação em uma grande revista, e os prêmios somente são para as pesquisas e produções acadêmicas, não existe galardão pelas atividades coletivas voluntárias e participação em políticas públicas (SALDIVA, 2016).

É exequível ações de mobilização sócio ambiental, mas para isso é necessária uma ação proativa no sentido de não encerrar a pesquisa na sua publicação, mas sim a partir daí começar uma ação mais intensa no sentido de angariar resultados cada vez mais expressivos.

Com ações de responsabilidade social muitos infortúnios poderão ser evitados, pois a sociedade e o meio ambiente estão expostos a grandes riscos. Neste ponto, práticas adotadas e programas desenvolvidos por empresas engajadas em prol da mobilização socioambiental podem trazer benefícios à coletividade. E para que as ações governamentais, empresariais e sociais sejam valorizadas é precípuo a mudança de atitudes, onde cada um pode ajudar visando um futuro cada vez melhor.

Para abortar esta questão foi elaborado esta pesquisa para perquirir a atuação em projetos de responsabilidade social em uma pequena empresa do setor de tecnologia de Presidente Prudente no estado de São Paulo. Elucidando a importância de iniciativas empresariais no combate à Dengue por meio de ações que promovam a sustentabilidade com atitudes preservacionista para o equilíbrio ambiental. Esse objetivo especificamente, divide-se em: acompanhar as ações de responsabilidade social da empresa no município de Presidente Prudente; Identificar os tipos de ações de responsabilidade social executadas pela empresa; Analisar os impactos causados com a ação de responsabilidade social realizada pela empresa; Apresentar a empresa caso analisada e suas práticas de mobilização sócio ambiental; Demonstrar a importância das ações socioambientais para evitar a proliferação do Aedes Aegypti; Apresentar os resultados: aceitação da comunidade e impactos ambientais.

Esta pesquisa foi autorizada pelo sistema gestor de pesquisa (SGP) da Unoeste e pelo Comitê de Ética em Pesquisa CEP protocolo 3339, para acompanhar as ações da empresa e o impacto nos stakeholders entre fevereiro de 2016 e agosto de 2017.

\section{METODOLOGIA}

Utilizou a pesquisa descritiva, por meio de uma abordagem qualiquantitativa e estudo de caso. O presente estudo possui rigor na clareza e sequencia logica das decisões de coleta de informações. Como instrumento de coleta de dados a pesquisa bibliográfica com extensa revisão teórica. Para triangulação dos dados a análise documental, observação direta e outros artefatos. O registro das informações foi organizado e interpretado sistematicamente e cuidadosamente.

Segundo Borges, Hoppen e Luce (apud FREITAS; JABBOUR, 2010, p. 11) a análise "consiste em examinar, categorizar, tabular e recombinar os elementos de prova, mantendo o modelo conceitual $e$ as proposições iniciais do estudo como referencias" Logo a análise é a parte que se forma a teoria, etapa fundamental para a pesquisa. Esta deve ser analisada com cuidado e com olhares intercalados na teoria e nas informações coletadas.

Foram transcritas todas a informações coletadas e enviadas para os respondentes para confirmação e certificação, a fim de não haver equívocos na interpretação dos dados. 
Em seguida a transcrição foi detalhada para identificar os dados relevantes da pesquisa. Os dados foram articulados com o referencial teórico para se obter consistências nos resultados. A presente pesquisa é do tipo PPG/PEIC com o Protocolo CPDI: 3339 e Protocolo da Plataforma Brasil: CAAE 57674416.7.0000.5515. Grupo de Pesquisa: Resíduos e Meio Ambiente.

\section{RESULTADOS}

A cidade de Presidente Prudente, historicamente, tem altos índices de pessoas contaminadas pelo vírus da Dengue. Diante disso a CREDSAT iniciou a campanha: "Bairro Consciente". Este projeto visa despertar as empresas do Bairro a se mobilizarem coletivamente na luta contra o mosquito Aedes Aegypti e ao mesmo tempo contribuir com o meio ambiente.

A estrutura de ação da empresa foi montada com a ajuda dos pesquisadores que auxiliaram na organização do processo, apesar da empresa estar estimulada a praticar o Responsabilidade Social ela somente dispunha de seus colaboradores para a elaboração do plano de ação, após reuniões ficou estabelecido a forma de trabalho e elaborado um planejamento estratégico.

A ação englobou a atuação de diversas empresas, 15 em sua totalidade que participam deste projeto, cada empresa tem sua faixa que foi confeccionada para o projeto "Bairro consciente". Diante dos resultados obtidos tem se que conforme tabela1 foram realizados 6 mutirões até o momento e suas respectivas quantidades de lixo recolhidos.

Tabela 1. Resultados das ações do mutirão de limpeza

\begin{tabular}{|c|c|c|}
\hline DATA & REALIZADO & $\begin{array}{c}\text { QUANT. DE } \\
\text { SACOS DE } \\
\text { LIXO }\end{array}$ \\
\hline $1^{\circ}$ MUTIRAO & $18 / 04 / 2016$ & $\mathbf{1 2}$ \\
\hline $2^{\circ}$ MUTIRAO & $29 / 08 / 2016$ & $\mathbf{9}$ \\
\hline $3^{\circ}$ MUTIRAO & $22 / 11 / 2016$ & $\mathbf{8}$ \\
\hline $4^{\circ}$ MUTIRAO & $01 / 03 / 2017$ & $\mathbf{9}$ \\
\hline $5^{\circ}$ MUTIRAO & $12 / 05 / 2017$ & $\mathbf{1 1}$ \\
\hline $6^{\circ}$ MUTIRAO & $08 / 08 / 2017$ & $\mathbf{1 3}$ \\
\hline
\end{tabular}

Fonte: Pesquisa de campo "08 ago. 2017"

Autoria: Alessandra Harumi Sakai dos Santos (2017)

Diante disso levantou-se a quantidade de lixo recolhido e os tipos de lixos recolhidos, que englobaram sapatos, vidros, garrafas, fraudas, piscinas, fios diversos, caixas de cigarro, sacolas plásticas, etc. A maioria do lixo recolhido possuía agua parada em seus recipientes.

Todos os mutirões realizados foram registrados por meio de fotos conforme imagens abaixo.

Figura 1. $1^{\circ}$ MUTIRÃO

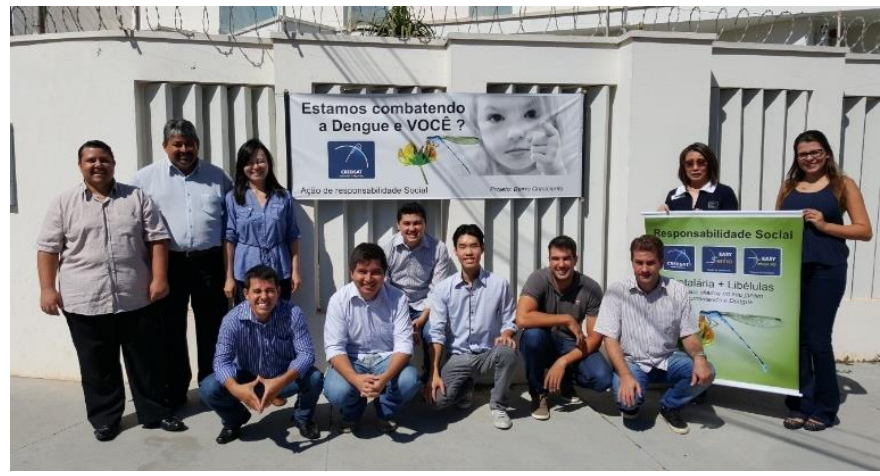

Fonte: Pesquisa de campo "18 abr. 2016"

Autoria: Alessandra Harumi Sakai dos Santos (2016) 
Figura 2. $2^{\circ}$ MUTIRÃO
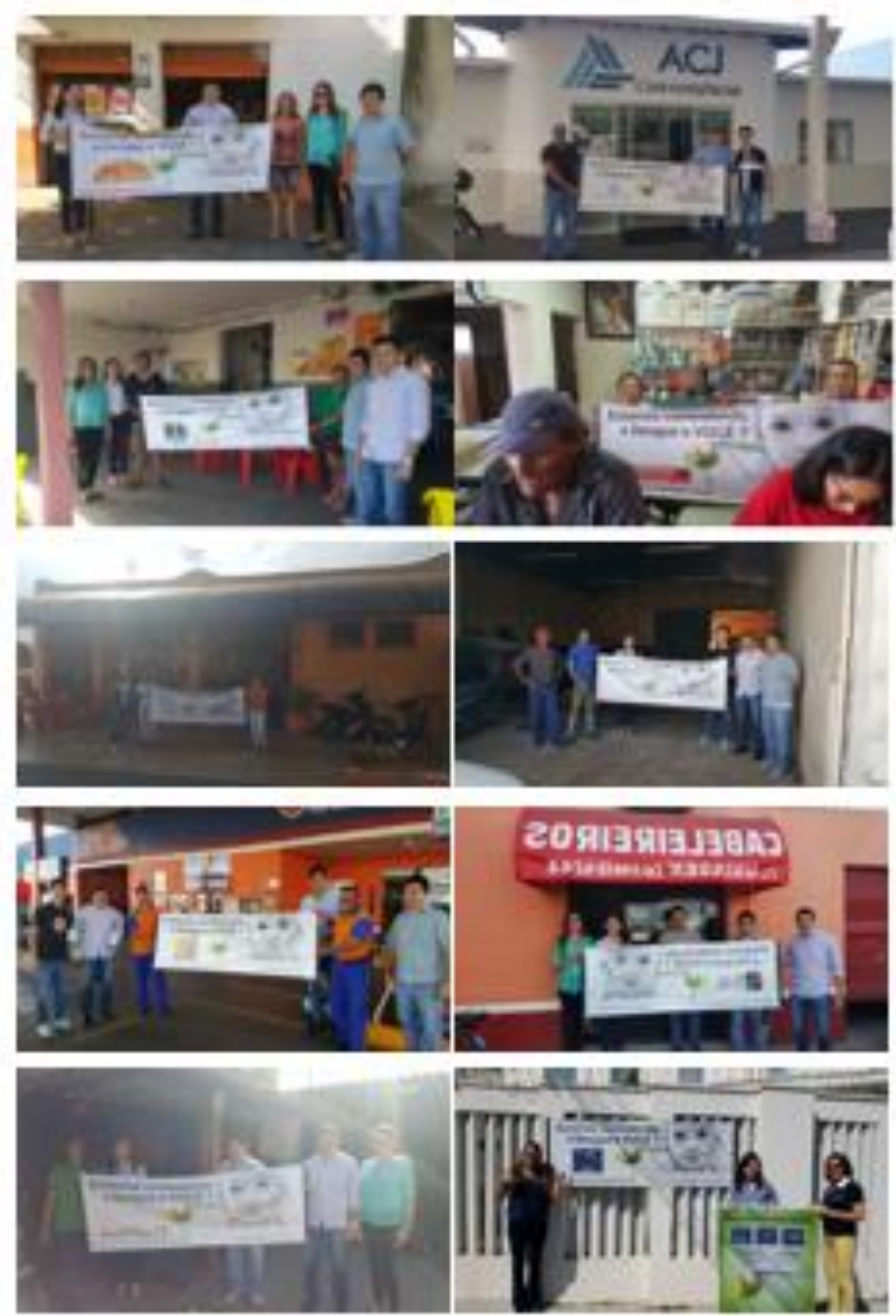

Fonte: Pesquisa de campo "29 ago. 2016"

Autoria: Alessandra Harumi Sakai dos Santos (2016)

Figura 3. $3^{\circ}$ MUTIRÃO

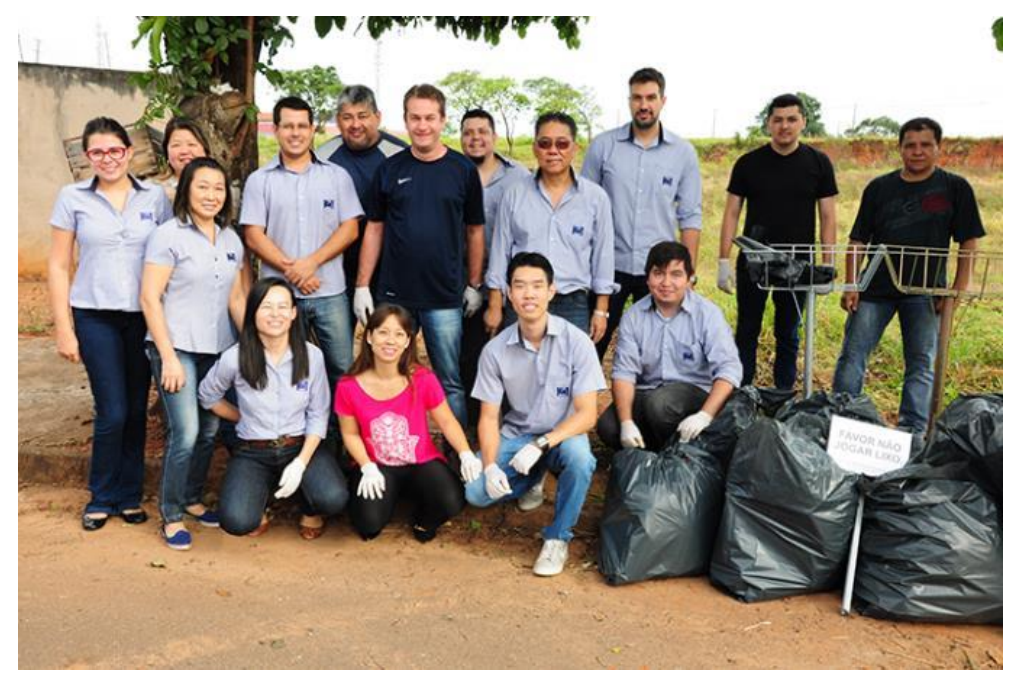

Fonte: Pesquisa de campo "22 nov. 2016"

Autoria: Alessandra Harumi Sakai dos Santos (2016) 
Figura 4. $4^{\circ}$ MUTIRÃO

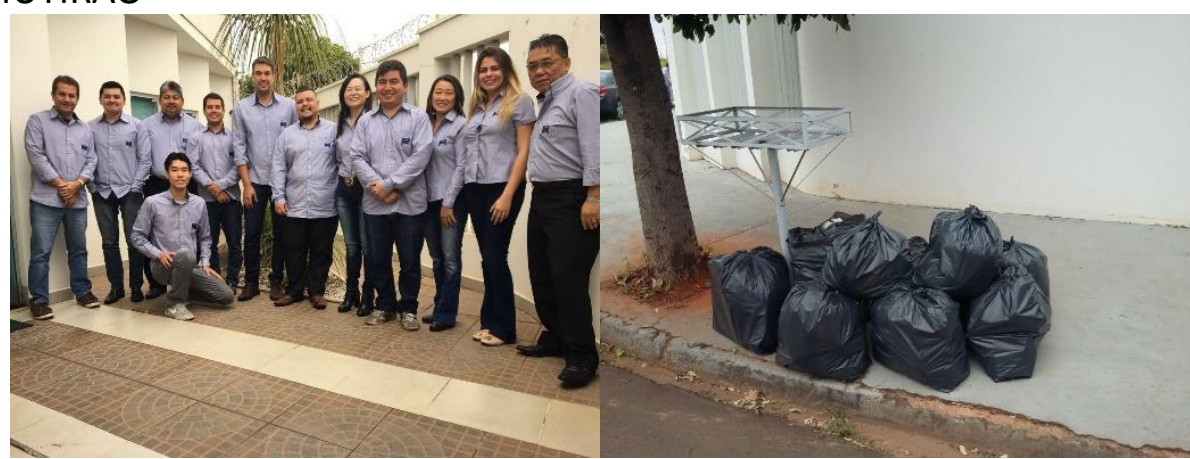

Fonte: Pesquisa de campo "01 mar. 2017"

Autoria: Alessandra Harumi Sakai dos Santos (2017)

Figura 5. $5^{\circ}$ MUTIRÃO

Fonte: Pesquisa de campo "12 mai. 2017"

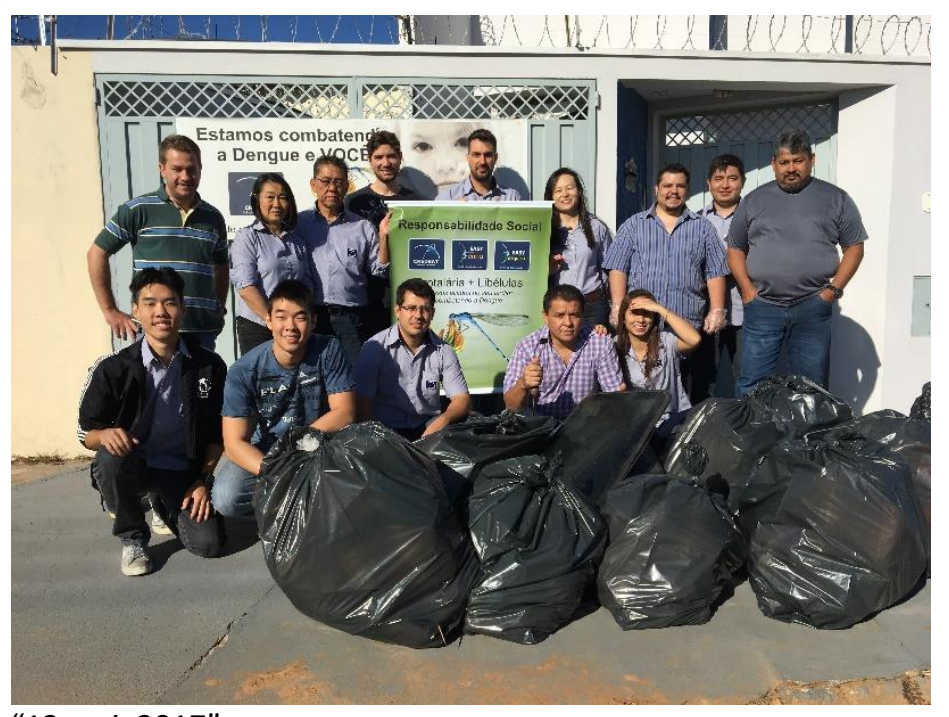

Autoria: Alessandra Harumi Sakai dos Santos (2017)

Figura 6. $6^{\circ} \mathrm{MUTIRÃO}$

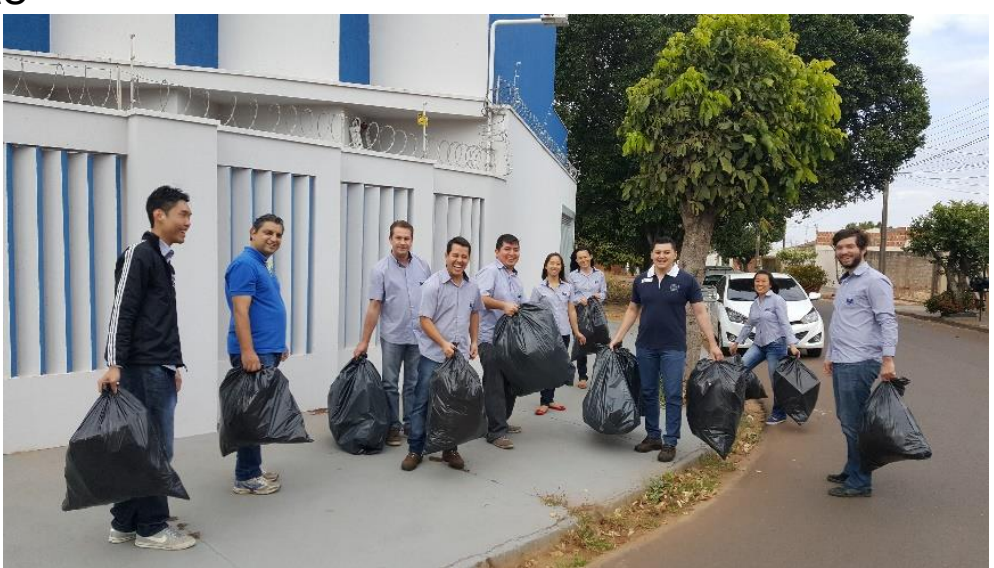




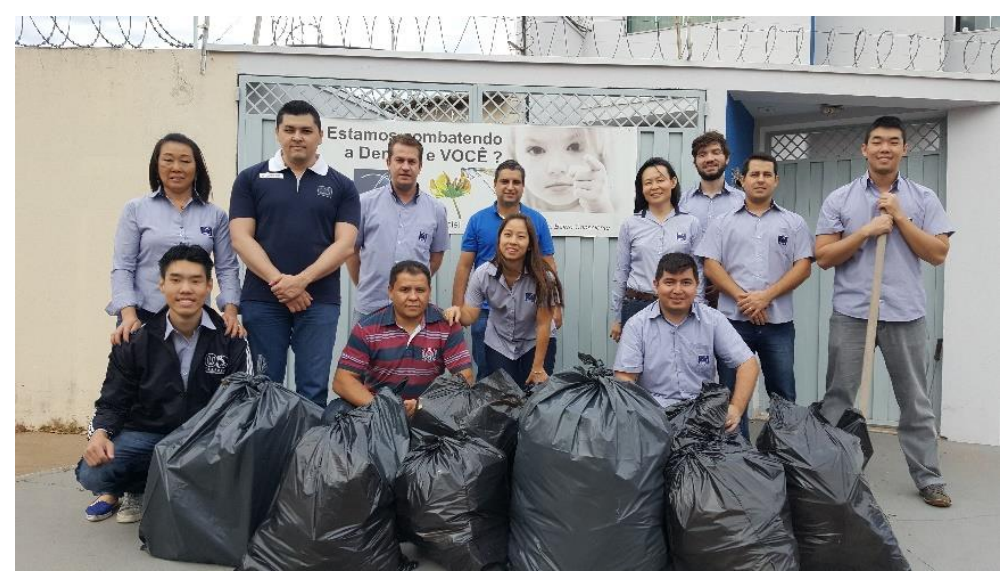

Fonte: Pesquisa de campo "08 ago. 2017"

Autoria: Alessandra Harumi Sakai dos Santos (2017)

Foram estabelecidas estratégias de responsabilidade social, as quais estão aprovadas, e obrigatoriamente devem ser incorporadas diariamente, nas rotinas, a fim de atingir os objetivos da organização. Estratégia envolve colocar em prática os planos e ações e acompanhar por meio de relatórios, indicadores e análise de resultados.

O Planejamento Estratégico é muito importante, é um conjunto de providências a serem tomadas pelo nível institucional para estabelecer a melhor direção a ser seguida pela empresa, (OLIVEIRA, 2011). São muitos, os fatores que influenciam diretamente as ações de uma empresa. Estes estão fora do controle e da previsão da organização. A CREDSAT trabalha fortemente a questão do planejamento estratégico e conforme Drucker (1995) a dinamicidade do planejamento estratégico na construção do futuro é fundamental para que se possa solidificar a visão de futuro que pretende.

Os resultados da pesquisa e entrevistas mostraram que empresas privadas podem mudar uma sociedade. Abaixo aponta-se cinco pontos comuns que emergiram da pesquisa:

1. Há um intenso esforço por parte de todos os colaboradores na realização das ações de responsabilidade social;

$\begin{array}{llrr}2 . & \text { No } & \text { Bairro Jardim } & \text { Novo } \\ \text { Bongiovani } & \text { as } & \text { empresas } & \text { estão } \\ \text { empreendendo esforços nas áreas do meio } & \\ \text { ambiente; } & & \end{array}$

3. A integração com a equipe e comunidade do bairro tem sido relevante no aspecto de boas práticas ambientais;

4. As iniciativas estão sendo relevantes para os negócios, pois fortificam a imagem da empresa;

5. As ações da CREDSAT têm favorecido três áreas a corporativa, a sociedade e o setor público.

Diante disso, é de extrema importância que todos os colaboradores tomem conhecimento de um planejamento estratégico. É indispensável o engajamento de todos neste processo para que as metas estabelecidas sejam angariadas. Todos na empresa possuem comprometimento para com os resultados esperados e tem acompanhamento e avaliação dos resultados em tempo real em relação as ações de responsabilidade ambiental.

\section{DISCUSSÃO \\ HISTÓRICO DA EMPRESA}

A CREDSAT iniciou sua atividade em outubro de 1994, com mais de 23 anos atuando no mercado de informações cadastrais, está sempre comprometida com a eficiência, a credibilidade de seus serviços e o sucesso de seus clientes. Entre os diferenciais estão a inovação nos conceitos de análises das consultas de cheques, documentos, cadastros de clientes e também a versatilidade no desenvolvimento de novos projetos aplicados às mais variadas necessidades do mercado. A postura empresarial da CREDSAT conquistou a 
confiança de empresas do segmento de automação comercial, estando presente em 23 estados brasileiros.

A CREDSAT tem como Missão: Permitir as pessoas e empresas, realizar seus SONHOS através de soluções inovadoras. Sua Visão é ser reconhecido no mercado pelo desenvolvimento de soluções inteligentes e atendimento de excelência. $E$ seus Valores são: envolvimento e comprometimento, mentalidade de liderança, honestidade, ética e moral, amizade, parceria e solidariedade, e responsabilidade socioambiental.

A empresa atualmente conta com 16 funcionários em sua sede em Presidente Prudente sendo: 5 no Departamento de Desenvolvimento, 3 no Departamento de Suporte Técnico, 2 no Departamento Administrativo Financeiro e 6 no Departamento comercial. Do total $56 \%$ são de descendência japonesa, o que implica em uma forte cultura preocupada com o meio ambiente.

\section{MOBILIZAÇÃO AMBIENTAL}

O ser humano desempenha um papel fundamental para o meio ambiente. Este por sua vez, vive em sociedade e precisa conciliar suas ações e atitudes harmonizando as com todos. Não somente visando o interesse individual, mas $\operatorname{sim} 0$ interesse coletivo englobando o todo no processo construtivo.

"[...] o homem é um ser racional e descobre os princípios que deve seguir para superar o estado de natureza e estabelecer o estado social", (DALLARI, 2016, p. 25). Assim o ser humano necessita estar em sociedade e o ato puramente racional estabelece isso. Todos buscam uma associação com outras pessoas para que possam viver em conformidade.

Dallari (2016) afirma que a finalidade da sociedade é o bem comum que visa a consecução de seus fins particulares através da cooperação de seus semelhantes. Pois o homem precisa viver em convivência e combinação com outros para que haja um equilíbrio entre as partes. $O$ autor expõe a importância de se viver harmonicamente em sociedade e muita das vezes essa vivência é precípua para se atingir os objetivos pessoais.

Uma sociedade organizada e

bem estruturada também pode contribuir para com o Meio Ambiente, pois o ser humano e a natureza estão sujeitos a muitas agressões ambientais. Sempre parte de um pressuposto que alguém precisa dar o primeiro passo para mobilizar uma ação.

Conforme Balbuena (2011, n. p.)

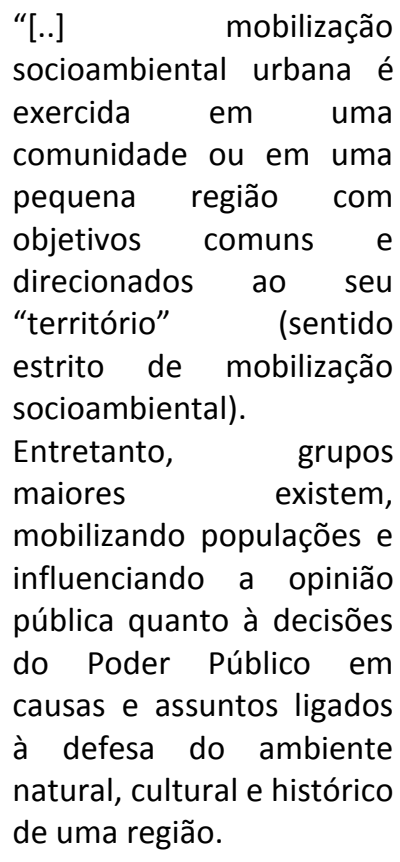

Do ponto de vista do autor a mobilização socioambiental deve de certa forma favorecer ambos os lados, criando ou despertando o desejo e a vontade de participar ou colaborar direta ou indiretamente de uma determinada ação.

Piccoli (2016, p.800) expõe:

A participação social deve
possuir caráter de
construção roletiva,
definindo-se e redefinindo
se como papel político. De
modo que ela seja
orientada pela mobilização
e por meio de ações
exercidas pelas diferentes
forças sociais. É essencial
um processor de
empowerment, mesmo
sendo este um termo
polissêmico e controverso.
Empowerment no sentido
de que pessoas e grupos
apreendem o poder para

A participação social deve construção coletiva definindo-se e redefinindo se como papel político. De modo que ela seja orientada pela mobilização e por meio de ações exercidas pelas diferentes forças sociais. É essencial um processo de empowerment, mesmo sendo este um termo polissêmico e controverso. de que pessoas e grupos apreendem o poder para 


\begin{abstract}
si mesmos e são impulsionados na melhoria de suas condições

de vida, aumentando sua autonomia na tomada de decisões para que possam exercer o controle social de maneira efetiva. A educação insere-se neste processo quando questiona-se o como fazer, o como possibilitar o empoderamento e o fortalecimento dos sujeitos nos espaços e/ou setores onde o controle social faz-se urgente e necessário. [...] Ela promove a equidade $\mathrm{e} a$ qualidade de vida por meio de suporte mútuo, cooperação, autogestão e participação em movimentos sociais autônomos, com práticas não tradicionais de aprendizagem e ensino que desenvolvem uma consciência crítica.
\end{abstract}

Desse modo, a concepção de mobilidade ambiental implica um novo papel dentro da sociedade, o de Empowerment. Hilsdorf (2010, n.p.) define o termo como "uma ação da gestão estratégica que visa o melhor aproveitamento do capital humano nas organizações através da delegação de poder". Empowerment é a descentralização das decisões, é delegar poder e responsabilidades as pessoas. E Piccoli (2016, p.800) aplica o conceito de Empowerment na sociedade como um todo, onde todos precisam exercer responsabilidades, ver o problema e agir de forma proativa. É destacado a importância da colaboração para fazer as coisas acontecerem. Com Empowerment as pessoas poderão mobilizar a sociedade na construção de um ambiente sustentável, através de práticas corretas e responsabilidade social.

É de extrema importância todos os seres humanos se mobilizarem por uma boa causa: a preservação do meio ambiente. Diversas doenças e acidentes são resultados das práticas errôneas adotadas pelas pessoas. A ação conjunta de instruir e orientar a população com uma educação ambiental pode trazer grandes resultados.

[...] a educação para a
cidadania representa a
possibilidade de motivar e
sensibilizar as pessoas
para transformar as
diversas formas de
participação em potenciais
fatores de dinamização da
sociedade e de ampliação
do controle social da coisa
pública, inclusive pelos
setores menos
mobilizados. Trata-se de
criar as condições para a
ruptura com a cultura
política dominante e para
uma nova proposta de
sociabilidade baseada na
educação para a
participação. (JACOBI,
2003, p. 203)

Contudo o autor salienta a importância da educação ambiental no processo de mobilização, que por meio de informações e orientações a sociedade se mobiliza a participar e cooperar com ações de responsabilidade ambiental. Ainda Jacobi (2003) apresenta a educação ambiental conforme a Política Nacional de Educação Ambiental (PNEA) como um processo onde o indivíduo e a coletividade edificam valores sociais, conhecimentos, competências, desenvolturas e atitudes direcionadas para a preservação ambiental. Ou seja as informações obtidas geram conhecimento, que por sua vez refletirão nos atos da sociedade. A informação é vital nesse processo, Jacobi (2003, p. 192) afirma que:

A postura de dependência e de desresponsabilização da população decorre principalmente da desinformação, da falta de consciência ambiental e de um déficit de práticas comunitárias baseadas na participação e no envolvimento dos cidadãos, que proponham 
uma nova cultura de direitos baseada na motivação e na coparticipação da gestão ambiental.

Aqui podemos trazer 0 Empowerment, onde o engajamento da sociedade no bem comum pode motivar a realização das ações sociais em prol do meio ambiente.

\section{GESTÃO AMBIENTAL}

$\mathrm{O}$ adensamento das situações ambientais instigou ao mesmo tempo o aumento da consciência das pessoas sobre a importância do meio ambiente natural. Aqueles que são possuidores de conhecimento, podem cobrar ações de responsabilidade social das empresas.

Silva et al. (2007, p. 6) em seu resultado de pesquisa afirma:

A gestão ambiental como
responsabilidade social
das organizações contribui
para que o mundo
globalizado e competitivo
em que se vive veja e,
principalmente, reconheça
que as empresas estão
cumprindo seu papel
diante do meio ambiente.
Além de ser uma
preocupação mundial, o
fator gestão ambiental,
também está sendo
considerado pelas
empresas como um meio
de serem bem vistas no
mercado.

Sendo assim, as empresas devem perfilhar ações que minimizem os impactos ambientais, promovendo ações de conscientização e gestão ambiental visando sempre a preservação do meio ambiente.

Atualmente as empresas estão preocupadas com a questão ambiental para ganharem competitividade e estão adotando práticas ambientalmente corretas. Os Stakeholders, que são as partes interessadas na empresa, estão atentas a questão ambiental.
Dias (2011), descreve que a Gestão Ambiental é utilizada para se referir a Gestão empresarial que se guia para prevenir problemas para o meio ambiente, visando o desenvolvimento sustentável.

Em função da cultura
ambiental predominante
nas empresas, a maior
parte dos esforços
tecnológicos e financeiros
que são aplicados nos
SGA está ligado a
aplicações de técnicas
corretivas, como, por
exemplo, reciclagem,
armazenamento de
resíduos, filtragem de
emissões, depuração, etc.
Para conseguir alcançar o
desenvolvimento necessário
sustentável é neas corretivas
que as medidas cor
sejam substituídas por
políticas prevenidas que
atuam sobre as origens
dos problemas, (DIAS,
2011, p. 103).

Desse modo, observa-se que é melhor prevenir do que corrigir. A ação proativa do Administrador é precípua neste contexto, pois antecipar aos problemas pode evitar futuramente graves problemas. Deve se pensar no todo, somos um sistema que deve interagir com as partes, onde todas as partes devem estar interligadas no bem comum visando a sustentabilidade.

Observe que Passos, Rabelo e Oliveira $(2015$, p. 28$)$ pontuam que

$$
\begin{aligned}
& \text { A gestão e política de meio } \\
& \text { ambiente nada mais é do } \\
& \text { que uma forma de } \\
& \text { administração integrada } \\
& \text { de uma região ou } \\
& \text { ambiente, visando ao } \\
& \text { equilíbrio do ambiente } \\
& \text { frente ao desenvolvimento } \\
& \text { e a exploração do capital. }
\end{aligned}
$$

Por fim, os autores explicam o conceito de Gestão voltada ao meio ambiente e a importância do equilíbrio entre produção e meio ambiente.

\footnotetext{
${ }^{1}$ SGA Sistema de Gestão Ambiental
} 


\section{CONCLUSÃO}

Salientando que as empresas no Brasil precisam reconhecer e compreender que elas não estão isoladas na sociedade e sim estão mergulhadas em um contexto social e ecológico fundamental para a sustentação da empresa. É preciso transformar a dimensão ambiental em um diferencial de mercado além de ser um diferencial de imagem e todos os resultados socioambientais necessitam ser divulgados e integrados a estrutura do negócio para que se ganhe força. Diante das evidencias literárias, a visão da complexidade das relações existentes na sociedade propicia uma nova postura. O município de Presidente Prudente possui diversas empresas e industrias, cabe a elas adotarem posturas de responsabilidade com o meio ambiente. Tais posturas devem ser praticadas e seus resultados analisados para uma possível avaliação e medição do grau de engajamento das organizações.

É necessário se construir novos saberes, através de novos conhecimentos que levem a conscientização e a urgência da mudança postural. A necessidade de se construir uma cidade sustentável é tanto de interesse econômico, social, ambiental e Nacional. Saber e conhecer o real motivo e as vantagens da pratica da responsabilidade socioambiental, trará novos olhares para a construção de um município sustentável que unirá a dinâmica ambiental e o desenvolvimento econômico com sustentabilidade.

A visão do Administrador ou do executivo deste século deve ser voltada para a preservação ambiental, e isso somente é possível quando estes adotam posturas de exemplos perante a sociedade. Dar o primeiro passo é fundamental, encabeçar projetos de responsabilidade social exige uma iniciativa proativa. $\mathrm{O}$ assunto em questão é de grande valia, visto que se faz necessário a promoção do desenvolvimento sustentável no município. Dessa forma sugere-se uma análise minuciosa das práticas de responsabilidade ambiental nas empresas do município de Presidente Prudente e então propiciar alternativas para $\mathrm{o}$ seu desenvolvimento.

O exemplo da CREDSAT demonstra claramente os benefícios socioeconômicos de uma ação Responsabilidade Social, afirma também que é possível que PMEs atuem na região que estão instaladas e provoquem uma mudança cultural dos stakeholders.

Ao mesmo tempo é possível que as PMEs façam ações Responsabilidade Social com baixo custo, as principais consequências foram: o surgimento de mídia espontânea, a melhoria de imagem e o fortalecimento do pertencimento regional. Acredita-se que empresas que praticam o Responsabilidade Social, fortalecem a marca valorizando seus produtos e tem mais condições de permanecer no mercado.

\section{REFERÊNCIAS}

DRUCKER, P. Administrando tempos de grandes mudanças. São Paulo: Pioneira, 1995.

BALBUENA, N. Mobilização socioambiental urbana. Ambiente em Revista, 2011. Disponível em< http://direitoambiental.jimdo.com/ambiente -em-revista/publica\%C3\%A7\%C3\%B5es-

cient\%C3\%ADficas/> Acesso em: 07 ago. 2016.

DIAS, R. Gestão ambiental: responsabilidade social e sustentabilidade. 2 ed. São Paulo: Atlas, 2011.

DALLARI, D. A. Elementos da teoria geral do Estado. 33. ed. São Paulo: Saraiva, 2016.

FREITAS, W. R. S.; JABBOUR, C. J. C. O estudo de caso(s) como estratégia de pesquisa qualitativa: fundamentos, roteiro de aplicação e pressupostos de excelência. In: ENCONTRO NACIONAL DE ENGENHARIA DE PRODUÇÃO, 3., 2010, São Carlos. Anais eletrônicos... São Carlos: ABEPRO, 2010. Disponível em: < http://www.abepro.org.br/biblioteca/enegep 
2010 th sto 122790 15342.pdf> Acesso em: 04 jun. 2016.

HILSDORF, C. O que é empowerment e como ele funciona?. O Portal da Administração. São Paulo, 2010. Disponível em < http://www.administradores.com.br/artigos/ carreira/o-que-e-empowerment-e-como-elefunciona/46403/> Acesso em: 05 ago. 2016.

JACOBI, P. Educação ambiental, cidadania e sustentabilidade. Cadernos de Pesquisa, n. 118, mar. 2003, p. 189-205. Disponível em< http://www.scielo.br/pdf/cp/n118/16834.pd f> Acesso em: 07 ago. 2016.

PASSOS, V. A.; RABELO, G. F.; OLIVEIRA, F. M. Resíduos sólidos urbanos: fundamento jurídico, influências no meio ambiente a responsabilidade da sociedade no seu gerenciamento. Ambiente em Revista, v. 5, p. 21-38, dez. 2015. Disponivel em: < https://drive.google.com/file/d/OBxx3ZdAK5 d2VWFk4SnFTUDkxems/view?pref=2\&pli=1> Acesso em: 07 ago. 2016.

PICCOLI, A. S., et. al. A educação ambiental como estratégia de mobilização social para o enfrentamento da escassez de água. Ciência \& Saúde Coletiva, Rio de Janeiro, v. 21, n. 3, p. 797-808, mar. 2016. Disponível em:< http://www.scielo.br/scielo.php?pid=S1413$\underline{81232016000300797 \& \text { script=sci abstract }>}$ Acesso em: 07 ago. 2016.

SALDIVA, P. Por uma cidade mais saudável. Pesquisa Fapesp, São Paulo, n. 241, p. 22 27, mar. 2016. Disponível em: http://revistapesquisa.fapesp.br/wpcontent/uploads/2016/03/022027 Entrevista-Saldiva 241.pdf?334154 Acesso em: 04 jun. 2016.

SILVA A. A., et. al. Gestão ambiental como responsabilidade social das organizações. In: ENCONTRO CIENTÍFICO E I SIMPÓSIO DE EDUCAÇÃO - UNISALESIANO. 1., 2007, Lins. Anais eletrônicos... Lins, 2007. Disponível em< http://www.unisalesiano.edu.br/encontro20 07/trabalho/aceitos/CC35214441800.pdf> Acesso em: 06 ago. 2016.

Recebido para publicação em 10/08/2017 Revisado em 22/08/2017 Aceito em 19/09/2017 